\title{
Comparative Study on the Tensile Performance of Box Frames Constructed by Keyed Joints and Dovetail Joints
}

\begin{abstract}
Shuo Wang, ${ }^{\mathrm{a}}$ Lu Chen, ${ }^{\mathrm{a}} \mathrm{Li}$ Jun Xu, ${ }^{\mathrm{a}}$ Hao Guan, ${ }^{\mathrm{a}}$ Sheng Zan Yan, ${ }^{\mathrm{a}}$ and Zhi Hui Wu,,${ }^{\mathrm{b}}$,
The box frame is a common structure in modern furniture, especially for cabinets. Accordingly, the joint contact force of the frame is important in evaluating the stability of classified furniture. In this study, a new type of keyed joint was proposed to alter the dovetail joint used in box frame structures. The tensile strength of the dovetail joint and the keyed joint in the frame were evaluated, and the contact forces and failure modes of these two joints were compared. Three levels $\left(T_{1}, T_{2}\right.$, and $\left.T_{3}\right)$ were proposed for the ratio of groove depth $(D)$ to inclined contact surface height $(H)$, under the condition of the same joint spacing and inclination angle considering the effects of keyed joint size on the contact force. Meanwhile, experimental analysis was performed on both sides $\left(S_{1}\right.$ and $\mathrm{S}_{2}$ ) of the dovetail joint. Results showed that the contact force of the joint under the gluing condition decreased in the order of $S_{2}>T_{2}>T_{3}>S_{1}>$ $T_{1}$. In terms of failure modes, the keyed joint could be maintained in good condition, whereas failure of the dovetail joint always occurred at the root of the tenon in the $S_{1}$ direction.
\end{abstract}

Keywords: Keyed joint; Frame; Failure mode; Tensile performance

Contact information: a: Department of Industrial Design, Nanjing Institute of Technology, 211167, Nanjing, China; b: Department of Furniture Design, Nanjing Forestry University, 210037 Nanjing, China;

*Corresponding author: $552192501 @ q q . c o m$

\section{INTRODUCTION}

Dovetail joints and keyed joints are the primary contact joints of the frame, which have higher contact force and anti-deformation capacity than other mortise-and-tenon joints (Li and Yang 2010; Wu 2012; Wang et al. 2015). The dovetail joint is a right-angle connection of flat wood, and the ladder-shaped tenon can join its corners to avoid being detached under stress (Xue 2013). The dovetail joint originated in architecture and was later extensively used in furniture design, becoming the most important means of joining in the manufacture of cabinets (Wang and Wu 2016). Research on the application of the dovetail joint in the field of wood construction has focused primarily on structural stiffness, failure mechanism, friction texture, etc. (Tannert et al. 2010; Pan et al. 2020), which serve as important reference values in the study of furniture structure.

Most previous studies on furniture structure have used the T-shaped and L-shaped joints as samples focusing on joint strength and failure mode (Li 2006; Derikvand and Ebrahimi 2014; Hu and Liu 2020). It has been determined through finite-element analysis that when the angle and matching amount are constant, the tension resistance of the dovetail joint increases with the tenon thickness factor (Nicholls and Crisan 2002; Yang 2017), and the tenon root is prone to yield failure under pressure (Zhang et al. 2019). In the frame, although the strength of the adhesive layer could enhance the contact force of the node to 
a certain extent when the dovetail joint is resisting external forces, the tensile strength depends primarily on the friction and pressure generated by the mortise-and-tenon joint (Altinok et al. 2009; Hu and Liu 2020; Hu et al. 2020).

The keyed joint is a common connection in modern woodworking that has the advantages of simple machining, convenient installation, and low cost. Common joints include round tenon and piece tenon, which are used primarily in right-angle joints and plane extensions and play a reinforcing and positioning role in furniture (Jensen et al. 2001; Chen et al. 2018; Chen and Lyu 2018; Hu et al. 2019). Research shows that the strength of the keyed joint depends on the penetration depth of the tenon, type of seam and adhesive, material (Maleki et al. 2012; Dalvand et al. 2014), etc. Most of the experimental methods adopt diagonal compression and diagonal stretching (Altinok et al. 2009) without considering the overall stress state of the frame in practical applications. Similar to the straight tenon joint, the contact force of the keyed joint depends on the friction caused by the interference fit and adhesive force of the adhesive layer (Hu et al. 2018), but it cannot be compared with the dovetail joint in terms of tensile resistance. However, considering the convenience and cheapness, if the keyed joint could be made to produce additional pressure, then the joint contact force could be further improved.

In the present work, a new type of keyed joint was proposed, aiming to alter the dovetail joint used in box frame. The keyed joint has a tapered shape with a lower width and upper width, which could be fitted closely with the groove of the same shape. This connection method could make the stress of each node of the frame achieve balance, and the anti-load capacity of each face is the same. This joint is different from other keyed joints. In addition to friction at the joint, this kind of connection could produce a certain degree of contact force, known as extrusion pressure, and obviously exceed the friction force (Hu et al. 2019). However, no corresponding research has been conducted on this kind of connection, particularly a comparison with a dovetail joint. Thus, an experimental demonstration is necessary.

The innovation of this study lies in the following aspects. First, through experimental research, the effects of keyed joints on the tensile properties of frames under three different levels are determined. Second, the contact forces and failure modes of the two types of joints in the frame are compared, and the feasibility of the new type of keyed joint application is evaluated.

\section{EXPERIMENTAL}

The research conducted in this study was divided in two parts. Part one presents the properties of the experimental materials. Part two consists of the preparation method of the specimens and the details of the experimental test.

\section{Materials and Test Method}

Figure 1 shows the materials of the specimens, which included MF-modified poplar wood (modified poplar wood impregnated with melamine-formaldehyde resin) and polyvinyl acetate adhesive (PVAC) emulsion (DINGLI, Taizhou, China). The detailed properties of the wood are shown in Table 1 (Yuan 2017). The selected wood was a chordsawn timber without scarring and defects, and the width was not less than $200 \mathrm{~mm}$ and the thickness was not less than $40 \mathrm{~mm}$. The $\mathrm{pH}$ value of PVAc emulsion was 6.7, the solid content was $48.6 \%$, and the viscosity was $0.64 \mathrm{~Pa} \cdot \mathrm{s}$. The amount of adhesive on the contact surfaces was approximately 150 to $200 \mathrm{~g} / \mathrm{m}^{2}$. 

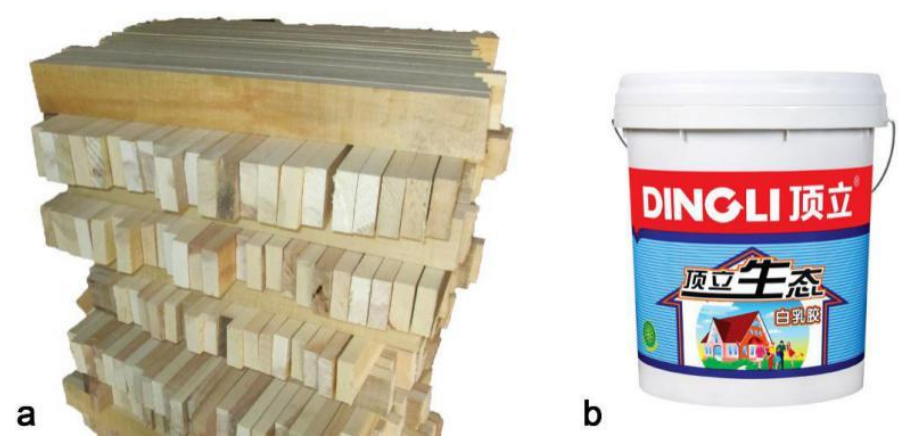

Fig. 1. Materials: (a) MF-modified poplar wood; (b) PVAC emulsion

Impregnating treatment is a common method used to modify wood materials (Yuan 2017; Hu and Zhang 2020). The process of impregnation and modification of poplar is as follows: The resin was diluted with water to a $25 \%$ mass concentration solution for future use. The test material was placed in an airtight treatment tank that was first evacuated to $0.095 \mathrm{MPa}$ and held for $45 \mathrm{~min}$, followed by loading MF resin, elevating the tank air pressure to $0.8 \mathrm{MPa}$ for 2 hours, and then releasing the pressure to end the impregnation process. The modified material was air-dried to a moisture content of less than $30 \%$, then it was placed in an oven to dry, and finally a modified treated material with a moisture content of approximately $10 \%$ was obtained.

Table 1. Material Properties (Yuan 2017)

\begin{tabular}{|c|c|}
\hline Property & Value \\
\hline Air-dry density & $0.63 \mathrm{~g} / \mathrm{cm}^{3}$ \\
\hline Moisture content & $10 \%$ \\
\hline Dry shrinkage rate & $8.07 \%$ \\
\hline Parallel-to-grain compressive strength & $10.02 \mathrm{MPa}$ \\
\hline Perpendicular-to-grain compression strength & $8.82 \mathrm{MPa}$ \\
\hline Elasticity modulus & $6285.57 \mathrm{GPa}$ \\
\hline Tensile strength parallel-to-grain & $86.33 \mathrm{MPa}$ \\
\hline Shear strength & $18.61 \mathrm{MPa}$ \\
\hline Bending strength & $64.85 \mathrm{MPa}$ \\
\hline Hardness & $2327.69 \mathrm{~N}$ \\
\hline
\end{tabular}

All specimens were processed by computer numerical control (CNC) machine tools with a precision of $0.01 \mathrm{~mm}$ (ULI-WPC, YuLi, Shanghai China). The specimens were square with a size of $250 \mathrm{~mm} \times 250 \mathrm{~mm} \times 100 \mathrm{~mm}$; the thickness of the plate was $14 \mathrm{~mm}$, and the interference of the joint was $0.1 \mathrm{~mm}$. Figure 2 shows that the keyed joint specimen was cut from the bottom edge of the four plates with symmetrical edges at $45^{\circ}$, and then three grooves were equidistantly machined with a dovetail milling cutter (bevel angle $76^{\circ}$ ) (Nanjing Institute of Technology, Nanjing, China). Then, the three grooves were compacted to make a sealed frame around the grooves after inserting the key into the dovetail groove. Finally, the contact surface was sanded with sandpaper until the contact surface flattened with the outer surface. 


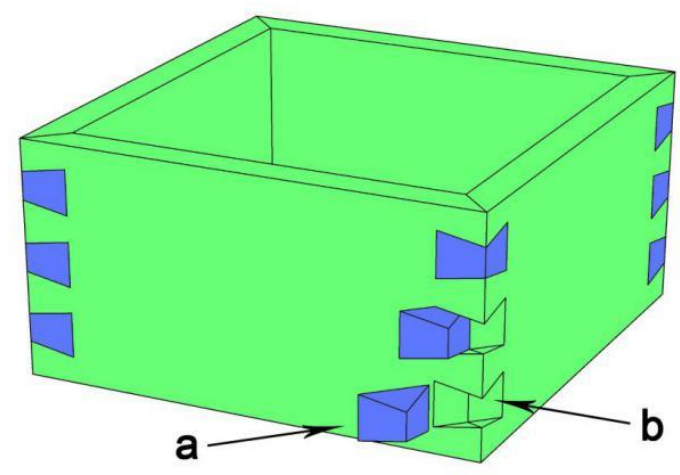

Fig. 2. Frame connected by keyed joint: (a) joint; (b) groove

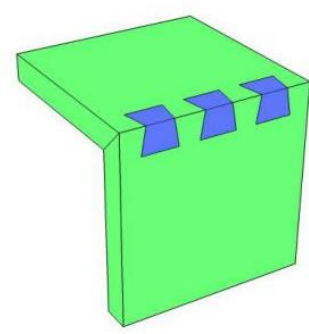

a

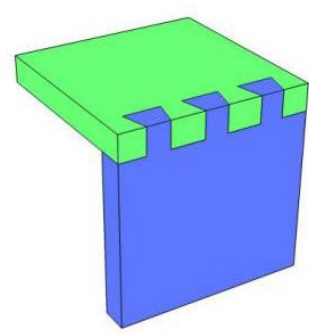

d

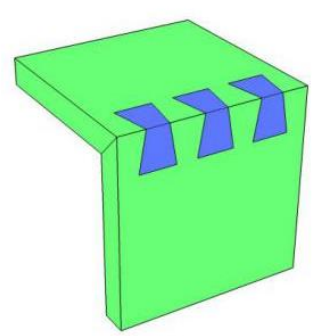

b

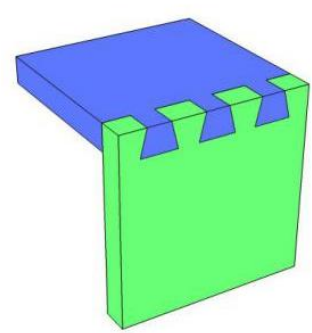

e

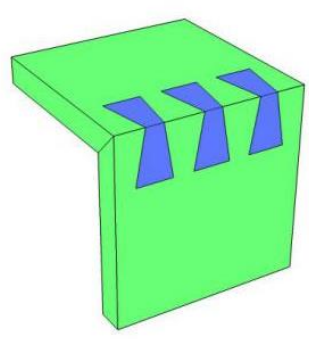

$\mathrm{c}$

Fig. 3. Five different specifications of joints: (a) $T_{1}$; (b) $T_{2}$; (c) $T_{3}$; (d) $S_{1}$; (e) $S_{2}$

Figure 3 shows five different sizes of joints in which a, b, and c are keyed joints, and the horizontal measurement algorithm of their sizes is as follows,

$$
T=(D / H) \times 100 \%
$$

where $D$ is the depth of the groove (mm), $H$ is the height of the contact surface ( $\mathrm{mm}$ ), and $T$ is the ratio of $D$ to $H$. Figure 4a shows the provisions for the three horizontal test pieces as follows: Fig. 3a is horizontal $T_{1}$, that is, $T_{1}=D_{1} / H \times 100 \%$; Fig. $3 \mathrm{~b}$ is horizontal $T_{2}$, that is, $T_{2}=D_{2} / H \times 100 \%$; Fig. $3 \mathrm{c}$ is horizontal $T_{3}$, that is, $T_{3}=D_{3} / H \times 100 \%$, where Fig. $3 \mathrm{~d}$ and Fig. $3 \mathrm{e}$ are dovetail joints, which are generated according to the different directions in which the tensions are on the dovetailing joint frame. Figure $3 \mathrm{~d}$ is horizontal $\mathrm{S}_{1}$, Fig. $3 \mathrm{e}$ is horizontal $\mathrm{S}_{2}$, and the mortise-and-tenon joint size is shown in Fig. $4 \mathrm{~b}$.

Figure 4 shows the related dimensional drawing of dovetail and keyed joints. In this study, a penetrating dovetail structure was adopted. The manufacturing method used in industrial production is mature and thus is no longer described in detail here. Before the 
test, all specimens were stored in a constant temperature and humid environment with moisture content of approximately $10 \%$.
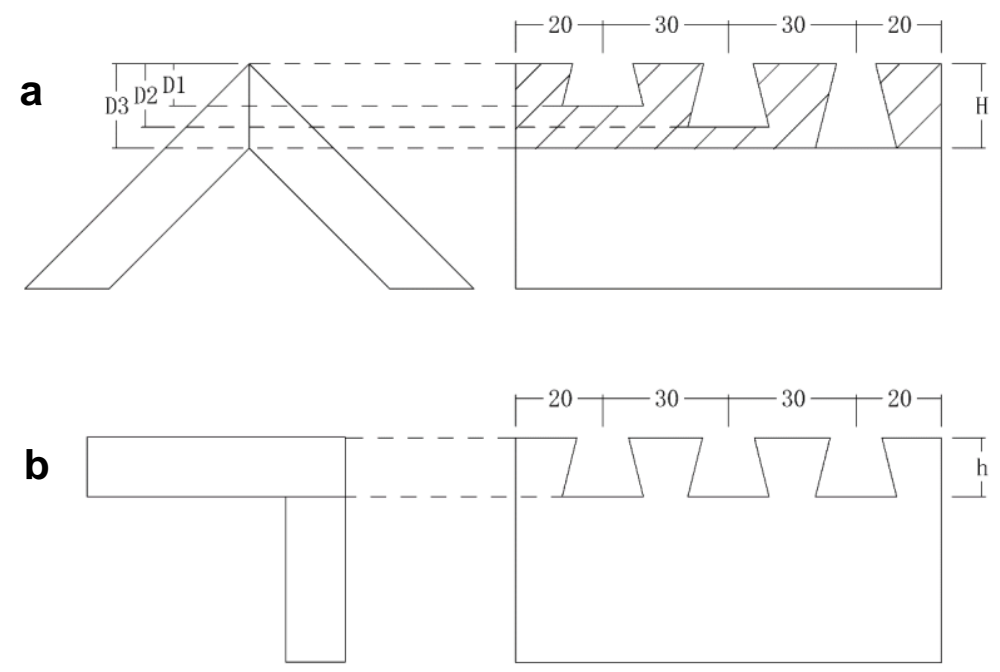

Fig. 4. Dimensions of grooves (mm): (a) keyed joint; (b) dovetail joint

\section{Testing Methods}

The primary equipment used in the experiment was a $20 \mathrm{KN}$ universal testing machine (AGS-X; SHIMADZU Corp., Kyoto, Japan) and a constant temperature and humidity box (DHG-905385-III; New Miao, Shanghai, China) (Fig. 5). The fixture used the steel mold designed by the authors. The detailed dimensions of the mold are shown in Fig. 6. This experimental method was considered on the basis of GB 10357.4-1989:-"Test of mechanical properties of furniture - stability of storage units." This experiment tested only the mechanical properties of the frame under a concentrated load; thus, the stress of the frame was primarily concentrated on the upper-end surface. The experimental loading method is shown in Fig. 7. The static load force was located in the middle of the upper plate of the specimen, $125 \mathrm{~mm}$ away from the end of the joint. The loading force was vertically and uniformly loaded with a speed of $10 \mathrm{~mm} / \mathrm{s}$, and the displacement was $6 \mathrm{~mm}$. Specimens of each type were measured five times.
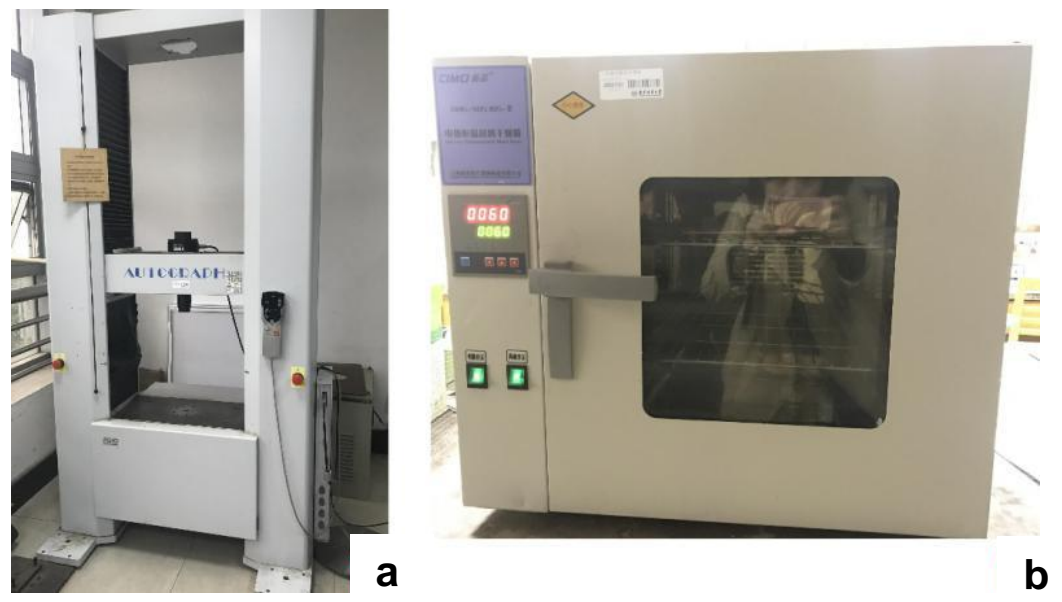

Fig. 5. Universal mechanics testing machine (a) and constant temperature humidity chamber (b) 

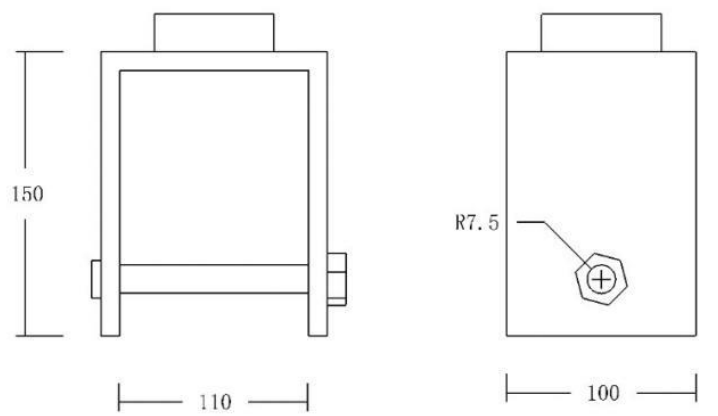

Fig. 6. Dimensions of mould used in this study $(\mathrm{mm})$

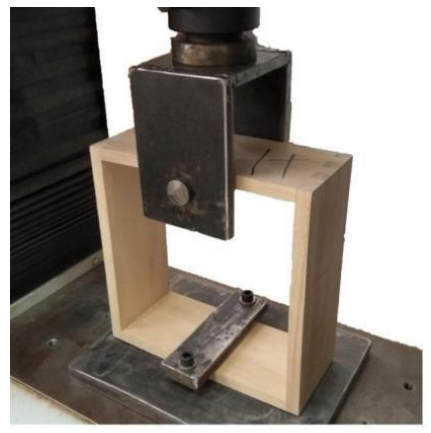

a

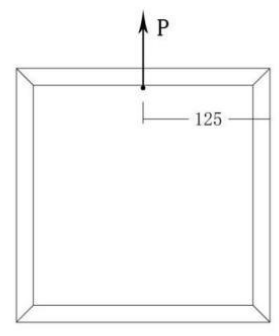

b

Fig. 7. Setup of measuring tensile strength of frame (a) loading method, (b) loading position (mm)

\section{RESULTS AND DISCUSSION}

\section{Tensile Loading-Displacement Curve and Load Extremum Analysis}

The typical load-displacement curve of the tensile behavior is shown in Fig. 8. The whole stretching process included two stages: yield fracture of the adhesive layer and yield deformation of the joint. For the whole loading process, elastic deformation (OA) is mainly manifested as the process of yield fracture of the adhesive layer. When the adhesive layer started to break, the joint contact force was derived from the static friction force generated by the mutual extrusion between the mortise and the tenon (Hu et al. 2019). When the external force was greater than the contact force at each joint, the joints started to slide, and the adhesive force disappeared, causing the contact force of the joints to change from static friction force to dynamic friction force. This process included elastic deformation and plastic deformation (AB).

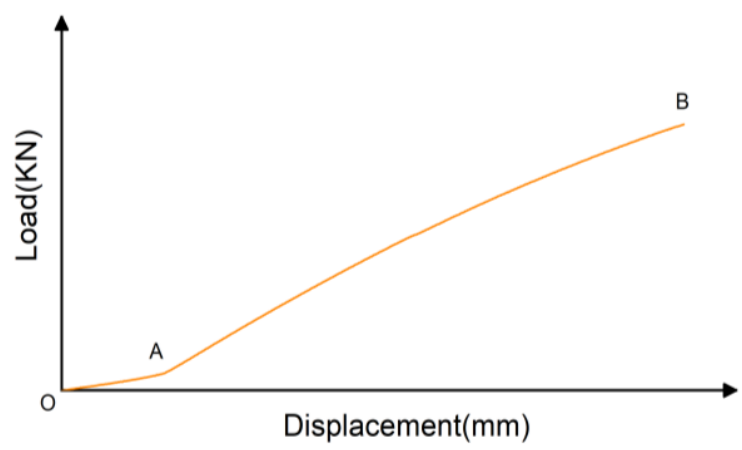

Fig. 8. Typical load-displacement curve 
The tensile behavior of the specimens at different levels is shown in Fig. 9. For $T_{1}$, part of the specimens failed to complete the whole stretching process because of the joint failure caused by the slipping of the keys, and the frame was unstable. For $T_{2}$ and $T_{3}$, all specimens had completed the whole stretching process with slight slipping in certain joints at the later stage of loading. For $S_{1}$, part of the specimens suffered joint failure because of the sudden fracture of the adhesive layer, and the stretching process was slightly stable. For $S_{2}$, all specimens had completed the whole stretching process without evident joint slipping, and the stretching process was quite stable.

Table 2 shows the extreme tensile load values of the specimens at different levels. The average load of $T_{2}$ was $2.631 \mathrm{kN}$, which was $66 \%$ higher than $T_{1}$ and $18.4 \%$ higher than $T_{3}$. Moreover, a noticeable difference in the average load between the two right-angled sides of the specimen connected by dovetail joints could be observed, and $S_{2}$ was $46.3 \%$ higher than $S_{1}$. The joint contact force of $S_{2}$ included the squeezing force and the adhesive force between the mortise and the tenon, whereas the contact force of $S_{1}$ primarily comprised the adhesive force. It can be seen from Table 3 that the significance difference was $\mathrm{F}=15.35$ and the corresponding test level was $\mathrm{p}=0.0005$. According to the value range of test level $\mathrm{p}$, i.e., $\mathrm{p}<0.001$, the value of $\mathrm{T}$ has a very significant impact on the tensile load value of the specimen.

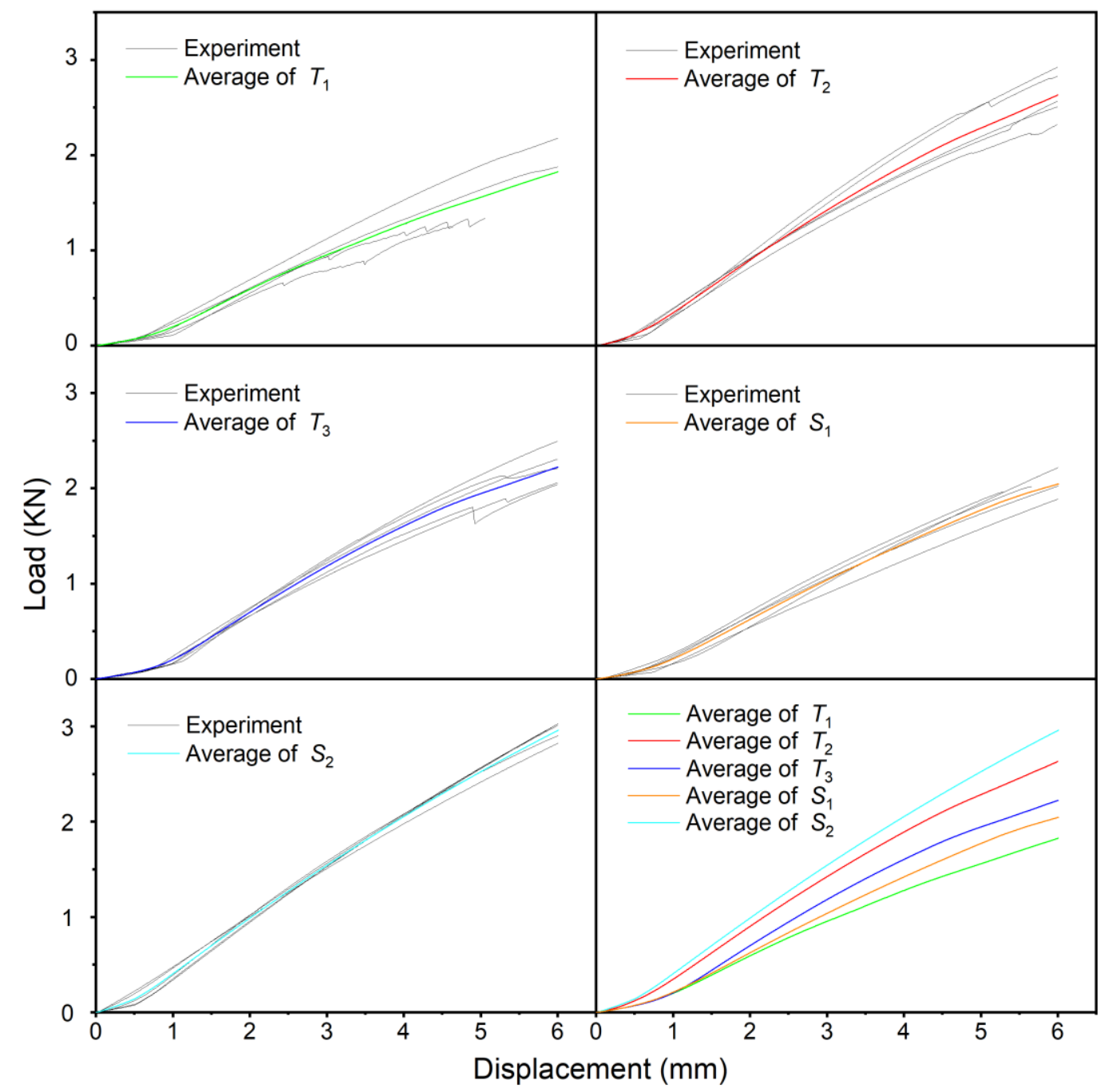

Fig. 9. The tensile behaviors of keyed joints and dovetail joints 
Table 2. Extreme Values of Tensile Load of Specimens at Different Levels

\begin{tabular}{|c|c|c|c|c|c|c|c|c|}
\hline Level & \multicolumn{5}{|c|}{ Value $(\mathrm{KN})$} & Average & SD & CV \\
\hline$T_{1}$ & 1.338 & 1.284 & 2.179 & 1.877 & 1.247 & 1.585 & 0.420 & $26.50 \%$ \\
\hline$T_{2}$ & 2.509 & 2.566 & 2.928 & 2.831 & 2.323 & 2.631 & 0.246 & $9.30 \%$ \\
\hline$T_{3}$ & 2.307 & 2.493 & 2.211 & 2.058 & 2.041 & 2.222 & 0.187 & $8.40 \%$ \\
\hline$S_{1}$ & 2.018 & 2.024 & 1.962 & 2.219 & 1.888 & 2.022 & 0.123 & $6.10 \%$ \\
\hline$S_{2}$ & 3.012 & 3.028 & 2.825 & 2.905 & 3.027 & 2.959 & 0.091 & $3.10 \%$ \\
\hline
\end{tabular}

Table 3. Analysis of Variance for Maximum Tensile Load at T Level

\begin{tabular}{|c|c|c|c|c|c|}
\hline Source & Sum of Squares & $\mathrm{df}$ & Mean Square & F value & $\mathrm{P}$ value \\
\hline Between Groups & 2.781 & 2 & 1.390 & \multirow{3}{*}{15.35} & \multirow{3}{*}{0.0005} \\
\hline Within Groups & 1.087 & 12 & 0.091 & & \\
\hline Total & 3.867 & 14 & 0.276 & & \\
\hline
\end{tabular}

\section{Comparison of Keyed Joints and Dovetail Joints}

The tensile strength of the specimen was determined by the contact force of each joint, i.e., a greater contact force of the joint means greater capacity of the structure to resist deformation. Under the same experimental conditions, the greater the anti-deformation capacity of the structure, the greater the contact force of the joints. Therefore, by comparing the loads of each group of specimens at the same distance of $6 \mathrm{~mm}$, the joint contact force could be determined at different levels.

\section{Joint contact force analysis}

Figure 9 also shows the loading-displacement behavior curves of the five groups of specimens. Any position during the stretching process could lead to the tensile resistance of the specimens in order. Therefore, the contact forces at different levels decreased in the order $S_{2}>T_{2}>T_{3}>S_{1}>T_{1}$. A comparison showed that the joint contact force of $S_{2}$ was remarkably higher than that of all the joints at the $T$ level, whereas $S_{1}$ had no evident advantage.

Figure 10 shows the possible influence trend of $T$ on the tensile strength, which could be inferred by comparing the average tensile load of the specimens at different levels. Therefore, the contact force of the keyed joint was nonlinear with the $T$, and a peak would appear near $T_{2}$.

As the $T$ value increases, the average tensile load of the keyed joint shows a trend of first increasing and then decreasing. In the study of Wang et al. 2020), under the state of stretching $5 \mathrm{~mm}$, the size of the keyed joints without glue has a significant effect on the tensile performance of the box frame. The tensile load also increases with the T value $(50 \%$, $75 \%$ and 100\%) increased first and then decreased, and the tensile load reached its maximum value at $\mathrm{T}=75 \%$ (Wang et al. 2020). This is similar to the results of the current study on glued keyed joints. It can be seen that the application of adhesive had no significant effect on the stretching trend of keyed joints. 


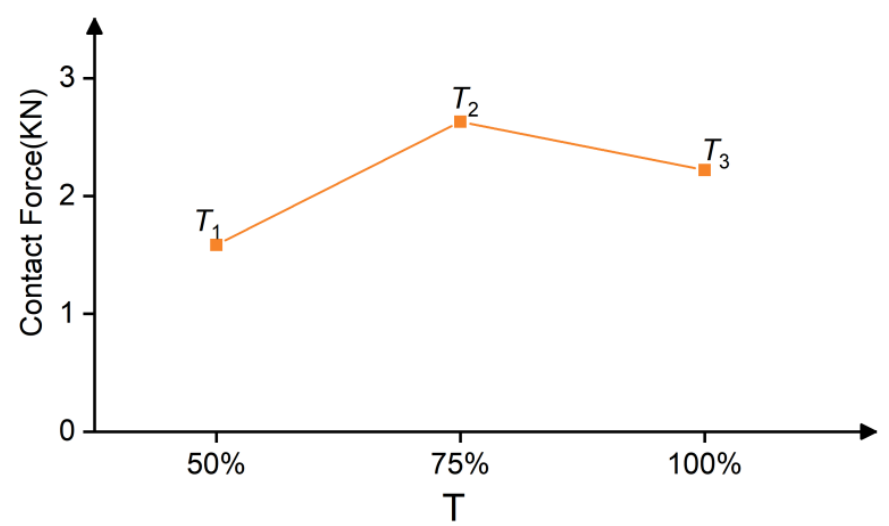

Fig. 10. Possible influence trend of $T$

\section{Failure mode analysis}

Figure 11 shows the typical failure modes of the five groups of specimens. The tenons did not break noticeably at all levels of $T$. However, the adhesive surface of $T_{1}$ broke quickly during the stretching process because of the small adhesive area and short tenon length. Moreover, $T_{1}$ was easier to break off than $T_{2}$ and $T_{3}$ under the same deformation. Although $T_{2}$ and $T_{3}$ had deviated slightly from the contact surface at the joint, they could still maintain a good contact state because the internal force of the material could overcome the friction at the joint after the load disappeared, which played a role in the recovery to a certain extent.
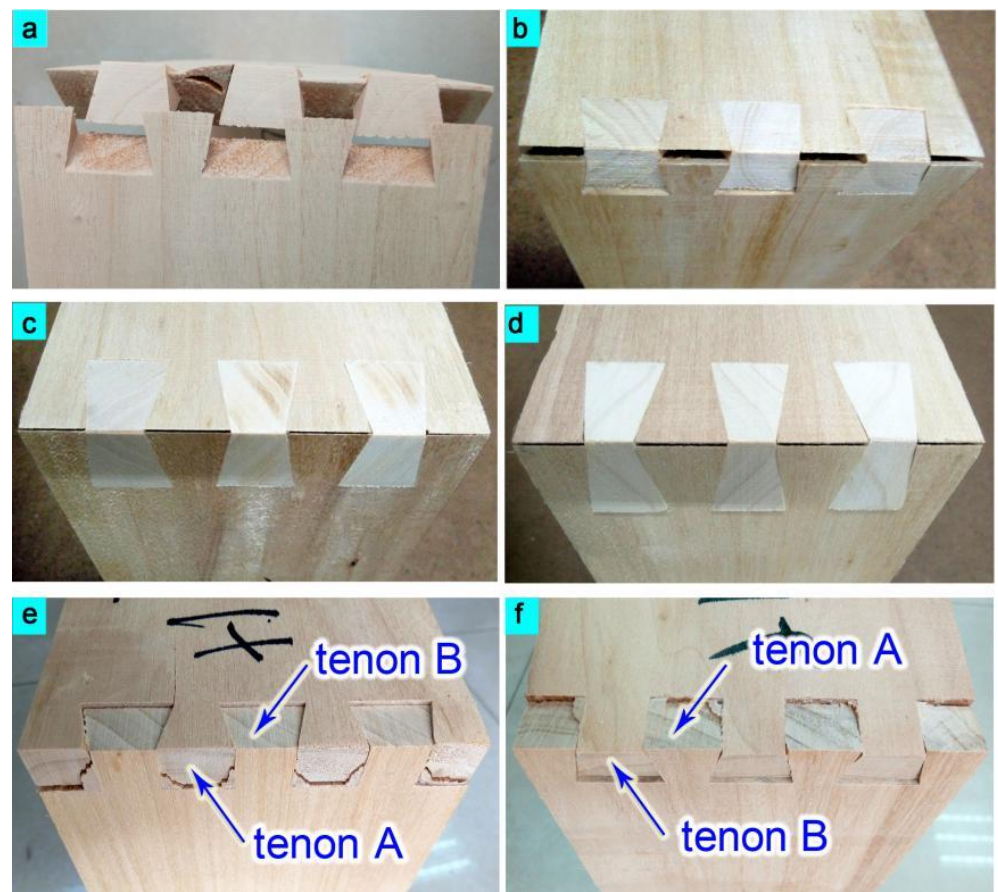

Fig. 11. Failure modes: (a) separated $T_{1}$; (b) unseparated $T_{1}$; (c) $T_{2}$; (d) $T_{3}$; (e) $S_{1}$; (f) $S_{2}$

As shown in Figs. 11e and 11f, both failure modes were reflected in the root of the tenon A of the dovetail joints. On the one hand, depending on the lever principle, the bottom received more tension force than the other position because the bottom of the tenons was the closest to the fulcrum. On the other hand, as shown in Fig.12, the tenon A and the 
tenon $\mathrm{B}$ of the dovetail joint occlude each other, and the tenon $\mathrm{B}$ receives the force of the tenon A perpendicular to its surface. This force restricts the tenon B in the $\mathrm{x}$-axis and $\mathrm{y}-$ axis directions. The displacement causes the adhesive layer at the bottom of the tenon B to be squeezed, and the adhesive layer formed is thinner. The tenon A only receives the force of tenon B on the X-axis, but not on the y-axis. As a result, the bottom of tenon A will form a larger space than the bottom of tenon B, and the adhesive will flow back to tenon A more easily. The bottom, therefore, produces greater adhesion on the contact surface. When the tenon was stretched, the fibers at the root of the tenon were easily torn because the two forces were in opposite directions. Moreover, after the load disappeared, the mortise-andtenon joints had a poor capacity to overcome the friction for returning to their original state. However, since the adhesive layer formed at the bottom of the tenon B is relatively thin, the adhesive force is insufficient to damage the tenon B during stretching.

Although the application of adhesive does not have much influence on the stretching tendency of the keyed joints, there is a certain difference in the destruction of the joints. When $\mathrm{T}=50 \%$, the unbonded joints did not detach after being stretched (Wang et al. 2020), while the glued joints partially detached.
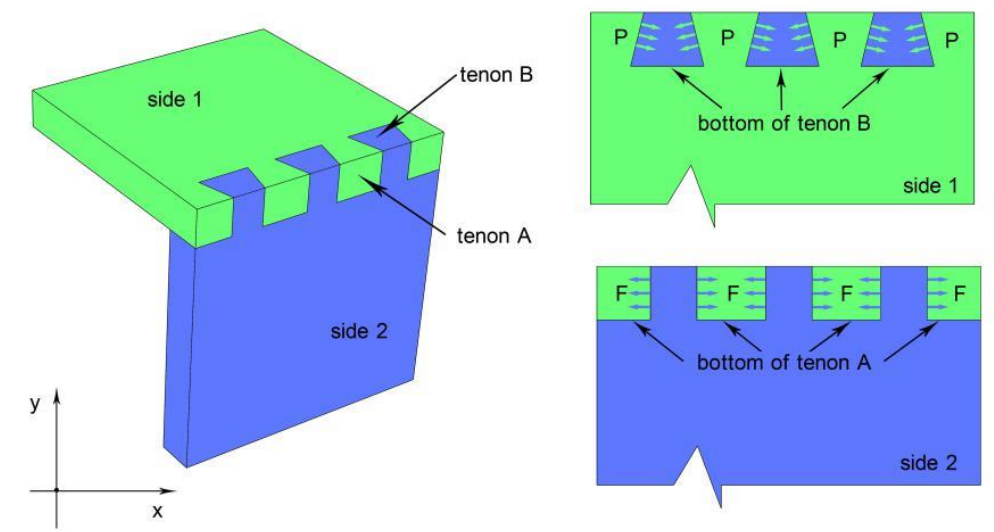

Fig. 12. Stress analysis of dovetail joint

\section{CONCLUSIONS}

The tensile properties of keyed and dovetail joints in box frames were investigated. Comparative analysis of joint contact forces and failure modes of the two frames was performed within the tensile displacement of $6 \mathrm{~mm}$. The primary conclusions can be summarized as follows:

1. As the ratio of groove depth to inclined surface height ( $T$ value) increases, the average tensile load of the keyed joint shows a trend of first increasing and then decreasing. $T_{2}$ is $66 \%$ higher than $T_{1}$, and $T_{2}$ is $18.4 \%$ higher than $T_{3}$.

2. Under the gluing condition, the order of the joint contact force was as follows: $S_{2}>T_{2}$ $>T_{3}>S_{1}>T_{1}$. Regarding the failure mode, the keyed joint could be kept in good condition, whereas dovetail joint failure always occurred at the root of the tenons in the $S_{1}$ direction.

3. When the value of $T$ is about $75 \%$, the contact force is obviously higher, which has certain advantages in practical application compared with that when the value of $T$ is about $50 \%$ and $100 \%$. 


\section{ACKNOWLEDGMENTS}

This work was supported in part by the Project of Philosophy and Social Science Research in Colleges and Universities of Jiangsu Province (Research on Structural Innovation of Detachable Mortise-and-Tenon Furniture, under Grant No. 2018SJA0390), in part by the Special Fund for Forest Scientific Research in the Public Welfare (under Grant No. 201404501), and in part by the Innovation and Development of Industrial Design Driven by Big Data (under Grant No. 2018SJZDA015).

\section{REFERENCES CITED}

Altinok, M., Tas, H. H., and Sancak, E. (2009). "Load carrying capacity of spline joints as affected by board and adhesives type," Scientific Research and Essays 4(5), 479483. DOI:10.1126/science.1169766.

Altinok, M., Tas, H. H., and Cimen, M. (2009). "Effects of combined usage of traditional glue joint methods in box construction on strength of furniture," Materials \& Design 30(8), 3313-3317. DOI: 10.1016/j.matdes.2008.12.004

Chen, M., Li, X. M., and Lyu, J. H. (2018). "Influence of dowel diameter and curing time on strength of double dowel joint," Wood Research 63(3), 591-598.

Chen, M., and Lyu, J. H. (2018). "Properties of double dowel joints constructed of medium density fiberboard," Maderas: Ciencia y Tecnologia 20(3), 369-380. DOI: 10.4067/S0718-221X2018005003801.

Dalvand, M., Derikvand, M., and Maleki, S. (2014). "Combined stress analysis of mitered spline furniture joints under diagonal loading," in: The 15th Conference Research for Furniture Industry, Karaj, Iran, pp. 15-22.

Derikvand, M., and Ebrahimi, G. (2014). "Finite element analysis of stress and strain distributions in mortise and loose tenon furniture joints," Journal of Forestry Research 25, 677-681. DOI: 10.1007/s11676-014-0507-5

GB/T10357.4 (1989). "Test of mechanical properties of furniture. Stability of storage units," Standardization Administration of China, Beijing, China.

Hu, W. G., Wan, H., and Guan, H. Y. (2018). "Study on contact force relaxation behavior of mortise-and-tenon joints considering tenon fits and grain orientations of tenon," BioResources 13(3), 5608-5616. DOI: 10.15376/biores.13.3.5608-5616.

$\mathrm{Hu}$, W., Liu, N., and Guan, H. (2019) "Experimental study of the contact forces and deformations of mortise-and-tenon joints considering the fits and grain orientations of the tenon," BioResources 14(4), 8728-8737. DOI: 10.15376/biores.14.4.

$\mathrm{Hu}, \mathrm{W}$., and Liu, N. (2020). "Numerical and optimal study on bending moment capacity and stiffness of mortise-and-tenon joint for wood products," Forests 11(5), 501. DOI: 10.3390/f11050501

Hu, W., Liu, N., and Guan, H. (2020). "Experimental and numerical study on methods of testing withdrawal resistance of mortise-and-tenon joint for wood products," Forests 11(3), 280. DOI: 10.3390/f11030280

$\mathrm{Hu}, \mathrm{W}$., and Zhang, J. (2020). "Bolt-bearing yield strength of three-layered crosslaminated timber treated with phenol formaldehyde resin," Forests 11(5), 551. DOI:10.3390/f11050551

$\mathrm{Hu}, \mathrm{W}$., and Liu, N. (2020). "Comparisons of finite element models used to predict bending strength of mortise-and-tenon joints," BioResources 15(3), 5801-5811. DOI:

Wang et al. (2020). "Tensile performance of frames," BioResources 15(4), 9291-9302. 
10.15376/biores.15.3.5801-5811.

Jensen, J. L., Koizumi, A., Sasaki, T., Tamura, Y., and Iijima, Y. (2001). "Axially loaded glued-in hardwood dowels," Wood Science and Technology 35(2), 73-83. DOI: $10.1007 / \mathrm{s} 002260000076$

Li, S. X. (2006). Research on Joint Strength of Frame Joints of Pine Furniture, Ph.D. Dissertation, Changsha University of Science and Technology, Changsha, China.

Li, X. J., and Yang, Y. F. (2011). "Study on joint strength of paulownia furniture based on connectionless quick disassembly structure," China Wood-Based Panels 18(10), 710. DOI:CNKI:SUN:CWBP.0.2011-10-002.

Maleki, S., Haftkhani, A. R., and Dalvand, M. (2012). "Bending moment resistance of corner joints constructed with spline under diagonal tension and compression," Journal of Forestry Research 23(3), 481-490. DOI: 10.1007/s11676-012-0288-7

Nicholls, T., and Crisan, R. (2002). "Study of the stress-strain state in corner joints and box-type furniture using finite element analysis (FEA)," European Journal of Wood and Wood Products 60(1), 66-71. DOI: 10.1007/s00107-001-0262-0

Pan, Y., Zhang, Q., Wang, X. Y., and Guo, R. (2020). "Study on mechanical model of dovetail joint of ancient wooden structure," Journal of Building Structures XX(XX), 1-10. DOI: 10.14006/j.jzjgxb.2019.0528.

Tannert, T., Lam, F., and Vallee, T. (2010). "Strength prediction for rounded dovetail connections considering size effects," J. Engineering Mechanics 136(3), 358-366.

Wang, S. (2016). "A box with keyed joint," China Patent No. CN205064471U.

Wang, S., Wu, Z. H., Chen. L., Yan. S. Z., Xu. L. J., and Guan. H. (2020). "Effect of mortise and tenon size on compressive and tensile strength of a box connected by dovetail keys," BioResources 15(3), 5776-5786. DOI:10.15376/biores.15.3.57765786.

Wang, L., Wang, Z., Zhou, X. W., Xiang, Q., and Zhao, R. J. (2015). "Connection mode and performance of wood structure joint," China Forest Products Industry 244(12), 50-53. DOI:10.19531/j.issn1001-5299.2015.12.015.

Wang, S., and Wu, Z. H. (2016). "Design exploration based on decorative mortise-andtenon structure," Furnit. 37(2), 57-61. DOI:10.19531/j.issn1001-5299.2016.04.009.

Wu, Z. H. (2012). "Interior and furniture design," in: Furniture Design, $2^{\text {nd }}$, China Forestry Press, Beijing, China, pp. 135-136.

Xue, K. (2013). Research on the Performance and Design Evolution of Traditional Furniture Mortise-and-tenon Structures, Ph.D. Dissertation, Nanjing Forestry University, Nanjing, China.

Yang, J. F. (2017). Study on the Influence of Mortise and Tenon Structure Parameters on its Mechanical Properties, Ph.D. Dissertation, Beijing University of Technology, Beijing, China.

Yuan, Y. J. (2017). The Material Contrast Research of Fast-growing Modified Poplar Wood and Furniture Material, Master's Thesis, Nanjing Forestry University, Nanjing, China.

Zhang, S., Yang, J. F., and Long, L. C. (2019). "Analysis of tensile properties of dovetail tenon," in: The $25^{\text {th }}$ Academic Annual Meeting of Beijing Mechanics Institute, Beijing, China, pp. 684-685.

Article submitted: September 2, 2020; Peer review completed: October 10, 2020; Revised version received and accepted: October 16, 2020; Published: October 22, 2020.

DOI: 10.15376/biores.15.4.9291-9302 